\title{
Reducing salt in bread: a quasi-experimental feasibility study in a bakery in Lima, Peru
}

\author{
Lorena Saavedra-Garcia', Vanessa Sosa-Zevallos ${ }^{1}$, Francisco Diez-Canseco', \\ J Jaime Miranda ${ }^{1,2}$ and Antonio Bernabe-Ortiz ${ }^{1,3,4, *}$ \\ ${ }^{1}$ CRONICAS Center of Excellence in Chronic Diseases, Universidad Peruana Cayetano Heredia, Av. Armendariz \\ 497, Miraflores, Lima 18, Peru: ${ }^{2}$ Department of Medicine, School of Medicine, Universidad Peruana Cayetano \\ Heredia, Lima, Peru: ${ }^{3}$ School of Public Health and Administration, Universidad Peruana Cayetano Heredia, Lima, \\ Peru: ${ }^{4}$ Escuela de Medicina, Universidad Peruana de Ciencias Aplicadas, Lima, Peru
}

Submitted 25 November 2014: Final revision received 23 March 2015: Accepted 14 April 2015: First published online 20 May 2015

\begin{abstract}
Objectives: To explore salt content in bread and to evaluate the feasibility of reducing salt contained in 'pan francés' bread.

Design: The study had two phases. Phase 1, an exploratory phase, involved the estimation of salt contained in bread as well as a triangle taste test to establish the amount of salt to be reduced in 'pan francés' bread without detection by consumers. In Phase 2, a quasi-experimental, pre-post intervention study assessed the effects of the introduction of low-salt bread on bakery sales.

Setting: A municipal bakery in Miraflores, Lima, Peru.

Subjects: Sixty-five clients of the bakery in Phase 1 of the study; sales to usual costumers in Phase 2.

Results: On average, there was $1.25 \mathrm{~g}$ of salt per $100 \mathrm{~g}$ of bread. Sixty-five consumers were enrolled in the triangle taste test: fifty-four ( $83.1 \%)$ females, mean age 58.9 (SD 13.7) years. Based on taste, bread samples prepared with salt reductions of $10 \%(P=0.82)$ and $20 \%(P=0.37)$ were not discernible from regular bread. The introduction of bread with $20 \%$ of salt reduction, which contained $1 \mathrm{~g}$ of salt per $100 \mathrm{~g}$ of bread, did not change sales of 'pan francés' $(P=0 \cdot 70)$ or other types of bread $(P=0 \cdot 36)$. Results were consistent when using different statistical techniques.

Conclusions: The introduction of bread with a $20 \%$ reduction in salt is feasible without affecting taste or bakery sales. Results suggest that these interventions are easily implementable, with the potential to contribute to larger sodium reduction strategies impacting the population's cardiovascular health.
\end{abstract}

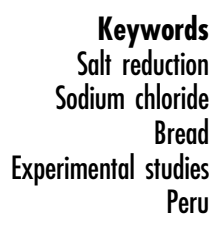

There is evidence that high salt intake has harmful effects on health, including raising blood pressure ${ }^{(1)}$ and increasing the incidence of cardiovascular and kidney disease $^{(2,3)}$ and stomach cancer ${ }^{(4)}$. As a result, the WHO recommends a salt intake for healthy adults of less than $5 \mathrm{~g} / \mathrm{d}$, equivalent to $2 \mathrm{~g} \mathrm{Na} / \mathrm{d}^{(5)}$. However, many populations consume twice the recommended intake ${ }^{(6)}$.

The overall salt content in Western foods could in some cases be excessive, especially processed foods ${ }^{(7)}$. Bread is one of the principal sources of salt worldwide ${ }^{(8)}$ and its salt content can vary from 0.4 to $1.6 \mathrm{~g}$ per $100 \mathrm{~g}$ of bread $^{(8-10)}$. As a consequence, some countries have established targets for the maximum salt content in bread. For example, in New Zealand ${ }^{(9)}$, there was a $7 \%$ reduction in the salt content in bread products over four years. In Ireland, through a salt reduction programme, the bakery industry established $0.45 \mathrm{~g}$ of salt per $100 \mathrm{~g}$ of bread as the average value in white and brown bread ${ }^{(11)}$. In 2007, as part of the Second National Nutrition and Health Program, one-third of bakeries in France reported reducing the amount of salt added to bread ${ }^{(12)}$. Similarly, in 2005 , the Spanish Confederation of Bakeries agreed to decrease salt content in bread from 22 to $18 \mathrm{~g}$ per $100 \mathrm{~g}$, reducing, on average, by $1 \mathrm{~g} / \mathrm{kg}$ of flour per year ${ }^{(12)}$. Thus, evidence from various countries shows there is a potential for salt reduction programmes to effect changes in the salt content of bread as a cost-effective strategy to improve public health.

In Peru, between 12 and $16 \%$ of the population aged 15 years and older has hypertension ${ }^{(13,14)}$, but no active public policies focus on reducing salt intake. On average, it has been reported that each adult in Peru consumes $2 \mathrm{~kg}$ 
of bread per month ${ }^{(15)}$, and the amount of salt added during preparation is variable, ranging from 16 to $25 \mathrm{~g} / \mathrm{kg}$ of flour ${ }^{(7)}$. There are several types of bread in Peru; the most common and one of the main products sold by Lima city bakeries is known as 'pan francés' bread ${ }^{(16)}$, made of flour, baking powder, salt, sugar, yeast and water. Therefore, the aim of the present study was to explore salt composition patterns in bread as well as to evaluate the feasibility of reducing the salt content in one type of bread, the 'pan francés' bread, at a municipal bakery in Lima, Peru.

\section{Methods}

\section{Objectives}

The present study had two main objectives, investigated in sequential order: (i) to explore the practices around salt usage during bread preparation as a proxy for determining salt contained in bread, as well as to determine a pragmatic and feasible amount of salt reduction in bread by using a sensory discrimination test (triangle taste test); and (ii) to evaluate a 6-month intervention focused on salt reduction in the preparation of bread and its impact on bakery sales using a quasi-experimental (pre-post intervention) study design. We hypothesized that the introduction of low-salt bread would not affect bread sales in the bakery during the period of study.

\section{Setting}

The study was carried out in Miraflores, a district in the south of Lima, Peru. According to the 2007 Peruvian census, the district has 85000 inhabitants, consisting mostly of wealthy people, high rates of literacy (96.1\%) and high access to health care $(80.0 \%)^{(17)}$. Through different municipal programmes, the district is implementing several strategies to promote healthy lifestyles, especially based on physical activity and adequate nutrition ${ }^{(18)}$. As a result, the municipal bakery in the district of Miraflores was selected by convenience to implement the present intervention. Usually, this bakery has a daily production of 5000 bakery products including bread as well as desserts and pastries, among others.

\section{Study phases}

The study had two phases performed in sequential order: the first was exploratory, lasting 2 months; the second was the intervention, performed over 6 months following the first phase.

\section{Phase 1: exploratory phase}

This phase was focused on estimating the salt contained in bread (target identification), as well as a triangle taste test.

\section{Target identification and estimate of salt content}

We determined the amount of salt used to prepare 'pan francés' bread as a way to estimate salt content in bread. For this, we decided to interview bakery staff regarding procedures of 'pan francés' preparation. The interview was performed by a trained nutritionist and included questions regarding number and specific activity of personnel, types of bread commercialized, bread characteristics including weight and ingredients used in cooking, recipe standardization, sales reporting, etc. Later, the same nutritionist verified directly the bread-making procedures; especially those related to recipes, weight of ingredients and bread-preparation techniques by observing cooking activities. Although the salt content in bread was not directly determined, standardized procedures regarding the weight of ingredients used during bread preparation were confirmed.

\section{Triangle taste test}

After estimating the salt content, a triangle taste test was conducted to determine the proportion of salt that could be reduced in 'pan francés' bread without detection by potential consumers. Two different bread preparations were used: one reduced salt by $10 \%$ per kilogram of flour and the second reduced salt by $20 \%$ per kilogram of flour. The amount of other ingredients used in 'pan francés' bread preparation was not changed in this process (Fig. 1).

Inclusion criteria for this part of the study included participants aged $\geq 18$ years and regular bread consumers who reported buying bread at least three times each week. Individuals were invited to perform the test. Informed consent for participation was obtained before starting activities. After consent, participants responded to a short questionnaire about sociodemographic data (age and gender) as well as information regarding consumption of 'pan francés' bread: average amount (number of units) of bread bought in a day and number of 'pan francés' eaten by the participant in a day. After that, participants were offered two different sets of bread coded with a random number. Each set had two identical samples and one odd sample, and were presented simultaneously in a predetermined random order. Procedures were explained to the participants by previously trained research staff and participants were asked to identify the odd sample, i.e. the $10 \%$ or $20 \%$ low-salt 'pan francés' bread. Each participant was exposed to two sets: one compared the common bread with the $10 \%$ low-salt 'pan francés' bread and the other compared the common bread with the $20 \%$ low-salt 'pan francés' bread. The samples were randomly presented to avoid positional bias since the middle sample is usually chosen as odd. If the participant was unable to determine which sample was different, $s /$ he was requested to guess. In addition, participants were asked to drink a glass of water between samples tasting to avoid sensory fatigue $^{(19)}$. To ensure consistency in food preparation, all 'pan francés' bread samples were prepared following the same protocol: the usual bakery recipe was changed only in the content of salt (Fig. 1). After completing the test, 
participants were required to identify the sample they believed to be the odd one, to indicate the degree of difference between samples (slight, moderate or high), the taste (salty), the acceptability of the taste of the samples and the option of buy this bread if available. The sensory discrimination test was planned to include sixty-five participants in total. This sample size provided $80 \%$ power at a $5 \%$ level of significance to have a $50 \%$ probability of the participant correctly selecting the odd sample instead of a $33 \%$ probability (by chance) in a triangle taste test ${ }^{(20)}$.

\section{Phase 2: intervention study}

Design

A quasi-experimental study, a non-randomized pre-post intervention, was performed to assess the impact of the implementation of low-salt 'pan francés' bread on sales. Information gathered in Phase 1 of the study regarding salt contained in bread as well as triangle taste test results were used to design the intervention. We decided to change only the salt content in 'pan francés' bread, as bakery personnel were concerned about the potential risk of reducing sales.

\section{Intervention and procedures}

One of the low-salt 'pan francés' breads assessed in the previous phase was selected to be introduced and sold in the bakery. To ensure appropriate blindness, consumers were not informed of the change in bread composition to reduce the potential impact of cognitive bias ${ }^{(21)}$. All the different types of bread normally offered were available during the intervention. At the end of every day, bread sales were recorded as part of the usual bakery routine. The implementation was planned to last 6 months, from April to September 2014.

\section{Outcome}

The main outcome was 'pan francés' bread sales, recorded daily according to a copy of sales vouchers and reported monthly in the bakery's accounting books. Information of these books was used for analysis. Secondary outcomes included the sales of other types of bread available in the bakery (desserts, cookies, pastries or similar products were not considered) collected in the same way as the main outcome. Data from previous bread sales, including 'pan francés' and other types of bread, were taken from available records of the bakery for up to 5 years before the implementation.

\section{Sample size}

Based on bakery records and usual bread sales (more than 20000 units of 'pan francés' bread sold each month), and assuming $5 \%$ level of significance, we had a power over $90 \%$ to detect a change in the regression coefficient of the intervention as small as $2 \%$ in the variation of bread sales.

\section{Statistical analysis}

After data entry was completed, the information was transferred to the statistical software package STATA 13 for Windows for analysis.

\section{Phase 1: triangle taste test}

To determine if the total number of correct responses for the total number of participants was statistically significant, we used the critical number of correct responses in a triangle taste test. Thus, we computed a $\chi^{2}$ test based on the following formula:

$$
x^{2}=\frac{(|4 a-2 f|-3)^{2}}{n},
$$

where $a$ is the proportion of participants who answered correctly, $f$ is the proportion of participants who did not answer correctly and $n$ is the number of participants ${ }^{(22,23)}$.

\section{Phase 2: intervention study}

Bread sales trends were assessed by graphical analysis. In addition, first-order differences in sales were calculated as the change of sales from one month to the next, and then plotted for visual verification of the variation in bread sales over time. Based on the pre-post intervention design of the study, sales of 'pan francés' bread were compared using the Student $t$ test using data from the 6 months prior to and after the intervention implementation. The same technique was used to compare the sales of the other types of bread also available in the municipal bakery, which were secondary outcomes.

In addition, linear regression analysis with robust standard errors was used to evaluate whether the introduction of saltreduced bread had an impact on bakery sales, considering the time (in months) in the model as a way to estimate the potential change in the trend of bread sales independently of the effect of the intervention, i.e. whether the sales increased or reduced over time without influence of the intervention. Different linear regression models using bread sales as well as first-order sales differences were assessed using information from records from the last 5 years as well as using just the last year alone. Similarly, linear regression was used to evaluate the impact of the intervention on the sales of other types of bread.

\section{Etbical approval}

This project was reviewed and approved by the Institutional Ethical Committee at Universidad Peruana Cayetano Heredia, Lima, Peru.

\section{Results}

\section{Phase 1: exploratory phase}

\section{Salt content of bread}

After verifying the method of bread preparation (see Fig. 1), $20 \mathrm{~g}$ of salt was combined with $1 \mathrm{~kg}$ of flour to prepare 40 units of 'pan francés' bread. Every unit of 'pan francés' bread 


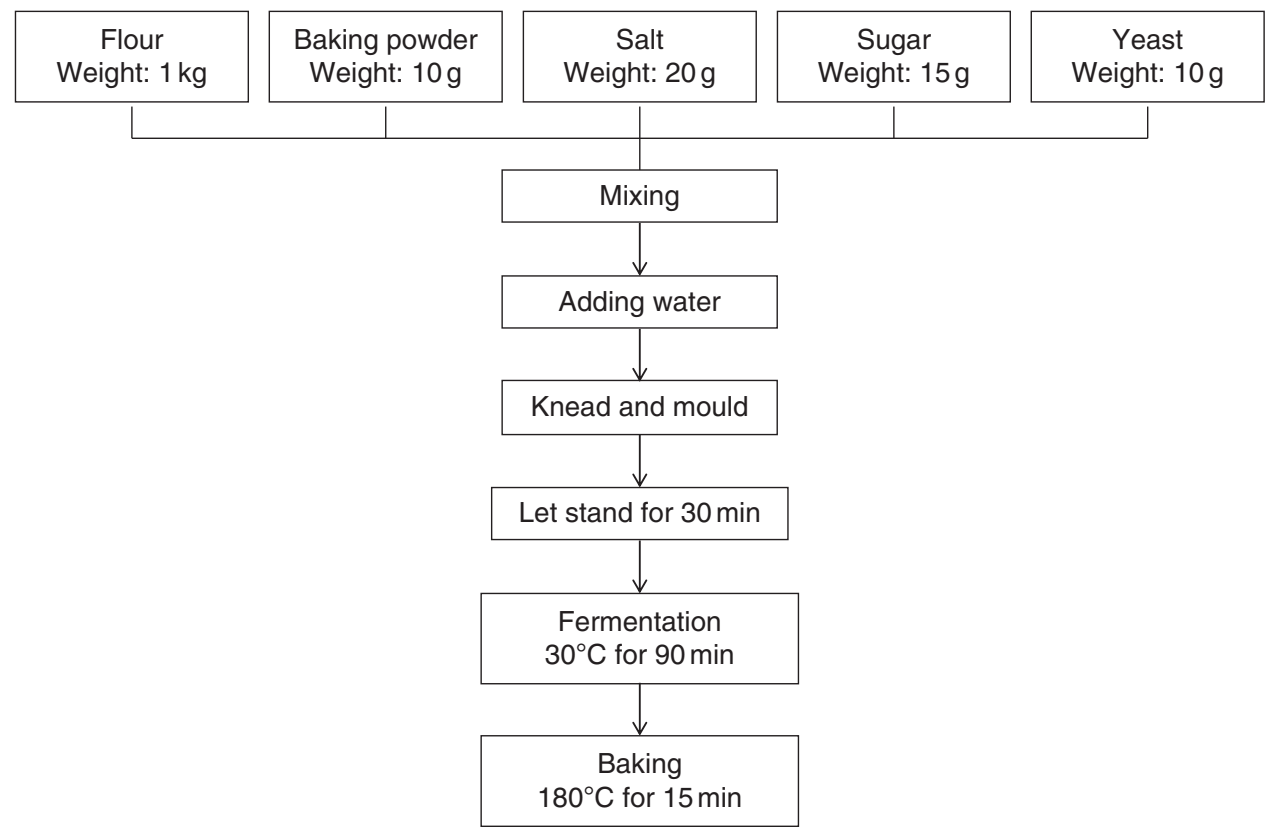

Fig. 1 Preparation protocol for 'pan francés' bread

(a)

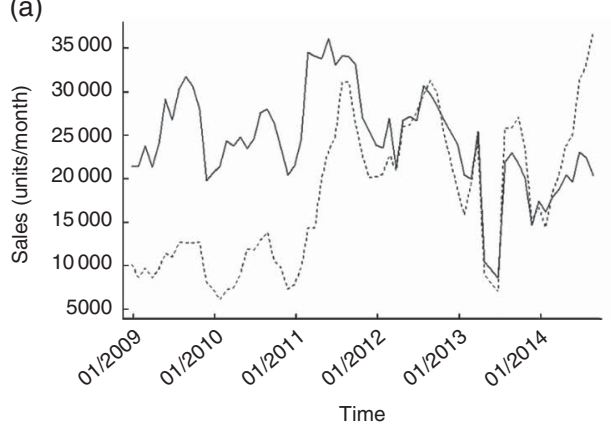

(b)

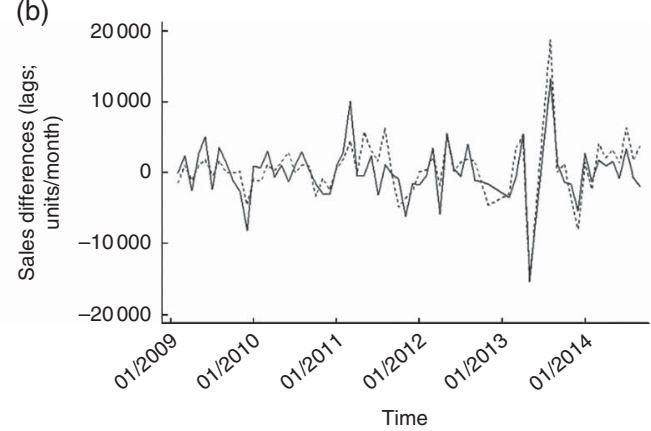

Fig. 2 Variation over time of (a) total sales and (b) first-order differences in sales for 'pan francés' bread ( $\longrightarrow$ ) and other types of bread (- - - - ) before and after the implementation* of $20 \%$ low-salt 'pan francés' bread ( $0.40 \mathrm{~g}$ of salt per unit; i.e. $16 \mathrm{~g}$ of salt/kg of flour) at a municipal bakery in Miraflores, Lima, Peru. ${ }^{*}$ The implementation was performed from April to September 2014

has $40 \mathrm{~g}$ of flour containing on average $0.5 \mathrm{~g}$ of salt $(1.25 \mathrm{~g}$ of salt per $100 \mathrm{~g}$ of bread). As a result, a reduction of $10 \%$ in salt content involved reducing the salt from 20 to $18 \mathrm{~g} / \mathrm{kg}$ of flour, or an average of $0.45 \mathrm{~g}$ per unit of bread. A reduction of $20 \%$ in salt content involved a change from 20 to $16 \mathrm{~g}$ of salt/ $\mathrm{kg}$ of flour, or $0.40 \mathrm{~g}$ per unit of bread.

\section{Triangle taste test}

A total of seventy bakery clients were contacted, but five $(7 \cdot 1 \%)$ did not meet the inclusion criteria, therefore only sixty-five were enrolled in the sensory discrimination test and analysed; mean age 58.9 (SD 13.7) years and fifty-four $(83.1 \%)$ were females. On average, bakery clients reported eating 3.6 (SD 1.8; range 1-10) units of 'pan francés' bread per day. Moreover, $23 \cdot 1 \%$ of the clients reported consuming five or more units of 'pan francés' per day.

Based on taste, 'pan francés' bread containing $0.45 \mathrm{~g}$ of salt per unit $(P=0.82)$ or $0.40 \mathrm{~g}$ of salt per unit $(P=0 \cdot 37)$ were not distinguishable from the usual bread containing $0.50 \mathrm{~g}$ of salt per unit. In addition, there were no differences between those who appropriately recognized the odd samples in the reported difference $(P=0.57$ for the case of $10 \%$ low-salt bread and $P=0.13$ for the $20 \%$ low-salt bread), salty taste $(P=0.56$ for the $10 \%$ low-salt bread and $P=0.80$ for the $20 \%$ low-salt bread) or reported acceptability $(P=0.36$ for the $10 \%$ low-salt bread and $P=0.99$ for the $20 \%$ low-salt bread). Moreover, after the test, over $60 \%$ of clients reported they would buy the low-salt bread if it were available.

\section{Phase 2: intervention study}

Based on the results of the sensory discriminatory test, the 'pan francés' bread containing $0.40 \mathrm{~g}$ of salt per unit (i.e. $16 \mathrm{~g}$ of salt $/ \mathrm{kg}$ of flour, a reduction of $20 \%$ in the salt content) was introduced because was not discernible from the regular 'pan francés' bread. The variation in bread 
Table 1 Results of Phase 2: intervention study; linear regression models assessing the impact on sales of implementation of the $20 \%$ low-salt 'pan francés' bread ( $0.40 \mathrm{~g}$ of salt per unit; i.e. $16 \mathrm{~g}$ of salt $/ \mathrm{kg}$ of flour) at a municipal bakery in Miraflores, Lima, Peru

\begin{tabular}{|c|c|c|c|c|c|c|}
\hline & \multicolumn{3}{|c|}{ Sales } & \multicolumn{3}{|c|}{ First-order sales differences } \\
\hline & Coefficient $^{\star}$ & $95 \% \mathrm{Cl}$ & $P$ value & Coefficient $^{*}$ & $95 \% \mathrm{Cl}$ & $P$ value \\
\hline \multicolumn{7}{|l|}{ Using 5-year data } \\
\hline \multicolumn{7}{|l|}{ 'Pan francés' bread } \\
\hline Time (in months) $†$ & $-99 \cdot 8$ & $-174 \cdot 1,-25 \cdot 6$ & 0.009 & $-13 \cdot 1$ & $-80 \cdot 2,54 \cdot 0$ & 0.70 \\
\hline Intervention & $-669 \cdot 4$ & $-4096 \cdot 6,2757 \cdot 8$ & 0.70 & $858 \cdot 1$ & $-2506 \cdot 5,4222 \cdot 7$ & 0.61 \\
\hline \multicolumn{7}{|l|}{ Other types of bread } \\
\hline Time (in months) $\dagger$ & $251 \cdot 8$ & $169 \cdot 1,334.5$ & $<0.001$ & 0.8 & $-76.4,77.9$ & 0.98 \\
\hline Intervention & $2765 \cdot 5$ & $-3240 \cdot 1,8771 \cdot 1$ & 0.36 & $2767 \cdot 6$ & $-1187 \cdot 5,6722 \cdot 8$ & $0 \cdot 17$ \\
\hline \multicolumn{7}{|l|}{ Using last-year data } \\
\hline \multicolumn{7}{|l|}{ 'Pan francés' bread } \\
\hline Time (in months) $\dagger$ & $-154 \cdot 8$ & $-998 \cdot 9,689.4$ & 0.69 & 99.9 & $-647 \cdot 4,847 \cdot 1$ & 0.77 \\
\hline Intervention & $3709 \cdot 3$ & $-1157 \cdot 5,8576 \cdot 1$ & $0 \cdot 12$ & 657.9 & $-4577 \cdot 5,5893 \cdot 2$ & 0.78 \\
\hline \multicolumn{7}{|l|}{ Other types of bread } \\
\hline Time (in months) $†$ & $685 \cdot 2$ & $-2054 \cdot 3,3424 \cdot 8$ & 0.59 & $531 \cdot 7$ & $-617 \cdot 3,1680 \cdot 7$ & 0.32 \\
\hline Intervention & $5210 \cdot 4$ & $-10346 \cdot 9,20767 \cdot 6$ & 0.47 & $1126 \cdot 3$ & $-6487 \cdot 4,8740 \cdot 0$ & 0.75 \\
\hline
\end{tabular}

${ }^{*}$ Robust standard errors were used to estimate coefficients and $95 \%$ confidence intervals.

†Time was included in the model to estimate the potential change of bread sales independently of the effect of the intervention.

sales and first-order differences in sales are shown in Fig. 2(a) and 2(b), respectively.

When comparing monthly bread sales, 'pan francés' sales were greater after the intervention than before the intervention (20 888 (SD 1609.7) v. 18107 (SD 2542.1) units/ month, respectively, $P<0 \cdot 05)$. Sales of other types of bread were similarly greater after the intervention than before the intervention (28615 (SD 6299.7) v. 19294 (sD 4994.3) units/month, respectively, $P=0 \cdot 02$ ).

When analysed using linear regression techniques, the intervention did not change 'pan francés' sales $(\beta=-669 \cdot 4$; $P=0.70)$ when data of the previous 5 years were analysed. Similarly, results were not significant $(\beta=3709 \cdot 3 ; P=0 \cdot 12)$ when only data from the last year were used. In addition, the intervention did not change sales of the other types of bread when using 5-year data $(\beta=2765.5 ; P=0.36)$, neither using last-year information $(\beta=5210 \cdot 4 ; P=0.47)$. Details of results are shown in Table 1 .

\section{Discussion}

Our results suggest that the introduction of bread with a reduced salt content is feasible without affecting taste or bakery sales: the sensory discriminatory test demonstrated that a reduction of $20 \%$ in the salt content of 'pan francés' bread was not discernible from the usual bread, and different statistical techniques showed that bakery sales were not affected by the introduction of this salt-reduced product. Taken together, this approach suggests a pragmatic route for implementation of similar strategies in other bakeries, both locally and internationally, thus contributing to wider prevention efforts.

\section{Salt reduction in bread without affecting taste}

The results of the first phase of the study showed that a sample of consumers of the municipal bakery were not able to discriminate bread with a $10 \%$ or $20 \%$ reduction in salt content from commonly consumed 'pan francés' bread. As taste can be one of the main barriers to the implementation of interventions reducing the salt content in food preparations ${ }^{(9,24)}$, our results demonstrate that low-salt bread samples were well accepted; furthermore, after the test, more than two-thirds of participants reported that they would buy the low-salt bread if available.

In addition, the present study found that, on average, 3.6 pieces of bread per day were consumed by each participant, equivalent to a daily consumption of $1.8 \mathrm{~g}$ of salt coming only from bread, assuming that each piece contains $0.5 \mathrm{~g}$ as reported. As a result, bread intake alone represents approximately $36 \%$ of the WHO recommended daily salt consumption ${ }^{(5)}$. In addition, approximately $25 \%$ of the sixty-five bakery clients enrolled in this phase of the study reported eating five or more pieces of 'pan francés' bread per day, equivalent to $2.5 \mathrm{~g}$ or more of salt per day.

\section{Feasibility of the salt-reduced bread intervention}

The introduction of $20 \%$ salt-reduced bread did not change bakery sales when considering 'pan francés' or other types of bread in the analysis. Moreover, our results were consistent when different statistical techniques were used to verify the potential impact of this pragmatic intervention on bakery sales. Thus, we believe it is feasible to reduce the amount of salt in bread in Peru and have, in the long term, a potential benefit on population health without increasing costs.

Salt reduction might have a detrimental effect on the production process of bread, as initially suggested by bakery staff. These effects could include an impact on dough handling and final bread quality characteristics, including shelf-life, bread volume and sensory characteristics ${ }^{(25)}$, any of which could have an impact on sales. In some cases, a partial substitution of sodium with potassium has been performed, 
especially in white bread ${ }^{(26)}$, but additional costs due to the potassium or other electrolytes needs to be considered in this process. In other cases, bread has been flavour-compensated with other substances such as yeast ${ }^{(27)}$. Despite this concern, many countries have started the introduction of salt reduction strategies in different foods and salt reduction in bread has been one of the common starting points in this process ${ }^{(9,12,28)}$. For example, the UK set a voluntary salt reduction target for bread of $1 \mathrm{~g}$ of salt per $100 \mathrm{~g}$ of bread, whereas New Zealand established $1 \cdot 12 \mathrm{~g}$ of salt per $100 \mathrm{~g}$ of bread.

By reducing the salt content of bread by $20 \%$, we have eliminated $4 \mathrm{~g}$ of salt $/ \mathrm{kg}$ of flour, equivalent to $0 \cdot 10 \mathrm{~g}$ per piece of bread. Given that clients reported eating 3.6 pieces of bread per day, this would lead to a reduction in salt intake of $0.36 \mathrm{~g}$ of salt per consumer per day. Recent modelling studies have concluded that sodium intake exceeds the recommended levels in almost all countries and, therefore, all populations would benefit from sodium reduction $^{(6,29)}$. In addition, as literature describes, the potential benefits are related not only to reducing blood pressure levels but also to a long-term reduction in cardiovascular events ${ }^{(2)}$. However, the amount of salt reduction that is feasible without affecting taste is not conclusive. For example, a previous study found that a one-quarter reduction in the sodium content of white bread can be delivered over a short time period without detection by consumers ${ }^{(30)}$. In this particular case, the salt reduction was performed weekly during six consecutive weeks. In another study, a $52 \%$ salt reduction in bread did not lead to lower consumption of bread compared with regular bread ${ }^{(31)}$. Moreover, when bread was flavourcompensated, a $67 \%$ reduction in salt did not lead to lower consumption. To the best of our knowledge, there is no significant evidence regarding the amount of salt that it is feasible to reduce without affecting taste. Accordingly, we believe it is necessary to better understand population characteristics before implementation of this kind of strategy, as some data suggest that salt preferences can be a learned process ${ }^{(24)}$. Therefore, it is possible that among participants with more frequent exposure to salt, the detection threshold may be gradually decreased over time. This provides a major opportunity to transit, gradually, towards lower salt practices that contribute to accrue longer-term health-related benefits. In this regard, there is substantial room for further improvements in health by reducing greater salt content in bread as well as other processed foods, but this process needs to be supported by enhanced surveillance and legislated approaches ${ }^{(6)}$.

Previous studies and experiences have demonstrated that the introduction of low-salt bread is technically feasible by making appropriate changes to the breadpreparation process ${ }^{(10,30)}$. Overall, the resulting product maintains the same bread characteristics and qualities, except for taste ${ }^{(25,32)}$. Our results suggest that it is possible to introduce a bread product with $20 \%$ salt reduction without compromising taste and sales.

\section{Strengths and limitations}

Strengths of the present study include its pragmatic nature as well as the use of several years of routine data. In addition, different statistical models were evaluated to show consistency of our results. However, the study has also some limitations. First, the quasi-experimental design might have been influenced by several confounders not assessed in the study. Nevertheless, we used an interrupted time-series design, where a string of consecutive observations equally spaced in time is interrupted by the imposition of an intervention ${ }^{(33)}$. Thus, with multiple measurements both pre- and post-intervention, we can easily address and control for confounding and regression to the mean, two of the most common problems in these types of studies. Second, results may not be generally applicable given that the study only used one bakery, selected by convenience. Moreover, the population of the selected district has information about healthy lifestyle choices through municipal programmes and therefore may be more conscious about the importance of salt reduction. However, based on previous reports, we believe that interventions such as the one described in the present study can be easily implemented in any setting and because the intervention was blinded to bakery clients, the potential impact of the other programmes implemented by the Municipality of Miraflores on our results is considered low. In addition, during the intervention, there was no health programme related to hypertension or excessive salt intake. Finally, it was not possible to corroborate if there was a change in the number of bakery consumers during the period following the intervention: for instance, some of the usual clients may have been replaced by other consumers. However, we maintained the consumers blinded to the intervention implementation and, thus, we reduced the possibility of impact on consumers' replacement.

\section{Conclusions}

A $20 \%$ salt reduction in bread can be a feasible intervention as bakery clients were not able to discern changes in taste in the bread. In addition, the implementation of this strategy did not reduce bread sales in a local bakery in Lima, Peru. This suggests that such an intervention can be implemented efficiently without sacrificing sales or financial revenues, a major consideration among bread producers.

\section{Acknowledgements}

Acknowledgements: The authors would like to thank the Municipalidad de Miraflores staff who allowed them to implement the intervention and the bakery personnel who helped with the introduction of the salt-reduced bread. The authors offer special gratitude to Carlos Contreras for his critical support in establishing this experiment. Financial support: L.S.-G., A.B.-O., F.D.-C. and J.J.M. are 
part of the CRONICAS Center of Excellence in Chronic Diseases, supported by the National Heart, Lung, and Blood Institute's Global Health Initiative under the contract 'Global Health Activities in Developing Countries to Combat Non-Communicable Chronic Diseases' (project number 268200900033C-1-0-1). A.B.-O. is supported by a Wellcome Trust Research Training Fellowship in Public Health and Tropical Medicine (grant number 103994/Z/ $14 / Z$ ). The funders had no role in the design, analysis or writing of this article. Conflict of interest: None. Authorship: L.S.-G., V.S.-Z., A.B.-O. and F.D.-C. designed all the study experiments, with substantial input from J.J.M. L.S.-G. and V.S.-Z. collected data and were responsible for the implementation of the intervention. A.B.-O. performed the statistical analyses. L.S.-G., V.S.-Z. and A.B.-O. drafted the first version of the manuscript. All the authors contributed to the revising of the manuscript for important content and gave their final approval of the version submitted for publication. Etbics of buman subject participation: The project was reviewed and approved by the Institutional Ethical Committee at Universidad Peruana Cayetano Heredia, Lima, Peru.

\section{References}

1. He FJ, Li J \& Macgregor GA (2013) Effect of longer term modest salt reduction on blood pressure: Cochrane systematic review and meta-analysis of randomised trials. BMJ 346, f1325.

2. Cook NR, Cutler JA, Obarzanek E et al. (2007) Long term effects of dietary sodium reduction on cardiovascular disease outcomes: observational follow-up of the trials of hypertension prevention (TOHP). BMJ 334, 885-888.

3. He FJ \& MacGregor GA (2011) Salt reduction lowers cardiovascular risk: meta-analysis of outcome trials. Lancet 378, 380-382.

4. D'Elia L, Rossi G, Ippolito R et al. (2012) Habitual salt intake and risk of gastric cancer: a meta-analysis of prospective studies. Clin Nutr 31, 489-498.

5. World Health Organization (2012) Guideline: Sodium Intake for Adults and Children. Geneva: WHO.

6. Powles J, Fahimi S, Micha R et al. (2013) Global, regional and national sodium intakes in 1990 and 2010: a systematic analysis of $24 \mathrm{~h}$ urinary sodium excretion and dietary surveys worldwide. BMJ Open 3, e003733.

7. Joossens JV, Sasaki S \& Kesteloot H (1994) Bread as a source of salt: an international comparison. J Am Coll Nutr 13, 179-183.

8. Brinsden HC, He FJ, Jenner KH et al. (2013) Surveys of the salt content in UK bread: progress made and further reductions possible. BMJ Open 3, e002936.

9. Dunford EK, Eyles H, Mhurchu CN et al. (2011) Changes in the sodium content of bread in Australia and New Zealand between 2007 and 2010: implications for policy. Med J Aust 195, 346-349.

10. Ferrante D, Apro N, Ferreira V et al. (2011) Feasibility of salt reduction in processed foods in Argentina. Rev Panam Salud Publica 29, 69-75.

11. Food Safety Authority of Ireland (2010) Salt Reduction Programme (SRP) - 2010 to 2011: Written Achievements and Undertakings Submitted by the Food Industry to the Food Safety Authority of Ireland. Dublin: FSAI.

12. World Health Organization (2009) Dropping the Salt. Practical Steps Countries are Taking to Prevent
Non-Communicable Disease Through Population Wide Dietary Salt Reduction. Geneva: WHO.

13. Instituto Nacional de Estadistica e Informatica (2014) Peru: Enfermedades no Transmisibles y Transmisibles, 2013. Lima: INEI.

14. Revilla L, Lopez T, Sanchez S et al. (2014) Prevalence of hypertension and diabetes in residents from Lima and Callao, Peru. Rev Peru Med Exp Salud Publica 31, 437-444.

15. Instituto Nacional de Estadistica e Informatica (2012) Peru: Consumo per capita de los Principales Alimentos 2008-2009: Encuesta Nacional de Presupuestos Familiares. Lima: INEI.

16. Montes C, Segura L, Miranda M et al. (1997) Consumo de Alimentos en el Peru 1990-1995. Lima: Asociacion Benefica PRISMA.

17. Instituto Nacional de Estadistica e Informatica (2007) Censos Nacionales 2007: XI de Poblacion y VI de Vivienda. Sistema de Consulta de Principales Indicadores de Pobreza. http://censos. inei.gob.pe/Censos2007/Pobreza/ (accessed November 2014).

18. Municipalidad de Miraflores (2014) Miraflores: Portal Oficial. Programa de Nutricion. http://www.miraflores.gob.pe/_ contenTempl2.asp?idpadre=6398 (accessed November 2014).

19. Hetherington MM (1996) Sensory-specific satiety and its importance in meal termination. Neurosci Biobehav Rev 20, 113-117.

20. Bi J (2006) Sensory Discrimination Tests and Measurements: Statistical Principles, Procedures and Tables. Ames, IA: Blackwell Publishing Ltd.

21. Haselton MG, Nettle D \& Andrews PW (2005) The evolution of cognitive bias. In Handbook of Evolutionary Psychology, pp. 724-746 [DM Buss, editor]. Hoboken, NJ: Wiley.

22. Mason R \& Nottingham S (2002) Sensory Evaluation Manual. Queensland: The University of Queensland.

23. Meilgaard M, Civille GV \& Carr BT (1999) Sensory Evaluation Techniques, 3rd ed. New York: CRC Press.

24. Li N, Prescott J, Wu Y et al. (2009) The effects of a reducedsodium, high-potassium salt substitute on food taste and acceptability in rural northern China. Br J Nutr 101, 1088-1093.

25. Belz MC, Ryan LA \& Arendt EK (2012) The impact of salt reduction in bread: a review. Crit Rev Food Sci Nutr 52, 514-524.

26. Braschi A, Gill L \& Naismith DJ (2009) Partial substitution of sodium with potassium in white bread: feasibility and bioavailability. Int J Food Sci Nutr 60, 507-521.

27. Yeh LT, Charles AL, Ho CT et al. (2009) A novel bread making process using salt-stressed baker's yeast. J Food Sci 74, issue 9, S399-S402.

28. Strazzullo P, Cairella G, Campanozzi A et al. (2012) Population based strategy for dietary salt intake reduction: Italian initiatives in the European framework. Nutr Metab Cardiovasc Dis 22, 161-166.

29. Mozaffarian D, Fahimi S, Singh GM et al. (2014) Global sodium consumption and death from cardiovascular causes. $N$ Engl J Med 371, 624-634.

30. Girgis S, Neal B, Prescott J et al. (2003) A one-quarter reduction in the salt content of bread can be made without detection. Eur J Clin Nutr 57, 616-620.

31. Bolhuis DP, Temme EH, Koeman FT et al. (2011) A salt reduction of $50 \%$ in bread does not decrease bread consumption or increase sodium intake by the choice of sandwich fillings. J Nutr 141, 2249-2255.

32. Lynch EJ, Dal Bello F, Sheenan EM et al. (2009) Fundamental studies on the reduction of salt on dough and bread characteristics. Food Res Int 42, 885-891.

33. Harris AD, McGregor JC, Perencevich EN et al. (2006) The use and interpretation of quasi-experimental studies in medical informatics. $J$ Am Med Inform Assoc 13, $16-23$. 